\title{
Mitigating the Impacts of COVID-19 on Global Child Health: a Call to Action
}

\author{
Anthony J. Garcia-Prats ${ }^{1,2}$ (D) - Ryan M. McAdams ${ }^{1} \cdot$ Mogomotsi Matshaba ${ }^{3,4,5} \cdot$ Lineo Thahane $^{4,5,6}$. \\ Sabrina M. Butteris ${ }^{1}$ - James H. Conway ${ }^{1}$ - Mandy Slutsker ${ }^{7}$ - Nicole E. St Clair ${ }^{1}$ - Heather Haq ${ }^{4,5}$
}

Accepted: 28 April 2021 / Published online: 11 May 2021

(C) The Author(s), under exclusive licence to Springer Nature Switzerland AG 2021

\begin{abstract}
Purpose of Review Severe acute respiratory syndrome coronavirus 2 (SARS-CoV-2), the cause of coronavirus disease 2019 (COVID-19), continues to affect individuals, communities, and health systems worldwide. Here, we highlight how COVID-19 threatens to jeopardize the tremendous gains made over the last few decades on improving children's health globally.

Recent Findings In contrast to adults, children with COVID-19 are less likely to develop severe disease requiring hospitalization or die as a direct result of infection. However, the pandemic will likely have other important health impacts disproportionately affecting vulnerable children globally. Possible effects include worsening of poverty and food insecurity; disruption of already strained routine child health services; damage to already imperiled healthcare workforces; a wave of mental health challenges; interruption of education; and increased risks of violence, abuse, exploitation, and neglect. These challenges notwithstanding, the response to COVID-19 may also provide opportunities, such as for health system strengthening, that could improve child health after the pandemic.

Summary The negative impacts of COVID-19 on global child health may be substantial. However, these are not foregone conclusions and much can be done to mitigate the worst outcomes. Child health providers should advocate for an equitable response to COVID-19 that prioritizes the health of vulnerable children and furthers the gains made in global child health.
\end{abstract}

Keywords Food insecurity $\cdot$ Malnutrition $\cdot$ Low- and middle-income countries (LMICs) $\cdot$ Healthcare workforce $\cdot$ Mental health · Routine childhood immunization

Topical Collection on Pediatric Global Health

Anthony J. Garcia-Prats

garciaprats@wisc.edu

1 School of Medicine and Public Health, Department of Pediatrics, University of Wisconsin-Madison, 2870 University Ave, Suite 200, Madison, WI 53705, USA

2 Desmond Tutu TB Centre, Department of Paediatrics and Child Health, Stellenbosch University, Tygerberg, South Africa

3 Botswana-Baylor Children's Clinical Centre of Excellence, Gaborone, Botswana

4 Department of Pediatrics, Baylor College of Medicine, Houston, TX, USA

5 Baylor College of Medicine International Pediatric AIDS Initiative at Texas Children's Hospital, Houston, TX, USA

6 Baylor College of Medicine Children's Foundation - Lesotho, Maseru, Lesotho

7 American Academy of Pediatrics, Itasca, IL, USA

\section{Introduction}

Severe acute respiratory syndrome coronavirus 2 (SARSCoV-2), the cause of coronavirus disease 2019 (COVID-19), has progressed to a global pandemic that will continue to impact communities and health systems worldwide for the foreseeable future. Thankfully, the vast majority of children with COVID-19 will have an asymptomatic or mild illness, and mortality in children has remained very low [1-4]. Despite this apparent diminished risk of severe COVID-19 disease, the pandemic will still affect children, both directly and indirectly, in multiple ways.

Significant strides have been made globally over the last three decades in improving child health. Global child and adolescent mortalities have fallen from 14.18 million deaths in 1990 to 7.26 million deaths in 2015 [5]. Despite such tremendous progress, this reduction has been unevenly distributed; $75 \%$ of deaths occur in lower income countries compared to $61 \%$ in 1990 [5]. Now, COVID-19 threatens to erase many 
of these gains, primarily through its indirect effects [6••]. If pandemic responses fail to prioritize the well-being of all children, the negative impacts of COVID-19 will pose serious, long-lasting threats to child health, with the most susceptible children, especially those in resource-limited settings, at greatest risk.

Here, we highlight the potential impacts of COVID-19 on global child health, particularly those in low- and middleincome countries (LMICs), and call for an equitable global response that prioritizes the most vulnerable children.

\section{Potential Impacts of COVID-19 on Global Child Health}

\section{Economic Impacts}

Physical distancing and large-scale community isolation mandates to mitigate viral transmission have had devastating economic consequences worldwide, which will continue even as they are gradually lifted. Precise estimates of the pandemic's economic impact vary, but all suggest that for the first time in 20 years, global poverty will increase. As new economic data has emerged, the World Bank has continued to increase estimates for the number of people newly living in extreme poverty (under $\$ 1.90$ a day) in 2020; from 62 million in April 2020 to $88-115$ million in June 2020, and more recently, to 119-125 million in January 2021 [7]. Models suggest that 40$50 \%$ of the anticipated increase in poverty secondary to the pandemic will likely be concentrated in sub-Saharan Africa and South Asia [7, 8], with 42-66 million more children globally expected to live in extreme poverty $[8,9]$. Poverty has ill effects on almost all aspects of a child's well-being, including physical health, neurodevelopment, educational attainment, and psychosocial well-being, which may persist throughout their lifetime [10]. As a consequence of the pandemic, more children will face food insecurity and develop undernutrition, posing immediate risks of morbidity and mortality and lifelong impacts on health and neurodevelopment [11-13]. Predictive models suggest that $18-23 \%$ of excess childhood mortality from indirect effects of COVID-19 will be due to an increased prevalence of undernutrition [6]. Interruptions in education will also have long-term effects on the well-being of children and may interrupt access to nutritional, health, and psychosocial support often provided through schools; the ability to mitigate these interruptions through distance learning is likely limited in many settings [9]. Although these negative effects may disproportionately affect LMICs, vulnerable children everywhere will be impacted, including those in highincome regions [14-16]. Through international cooperation and implementation of creative policies, there are opportunities to reduce the economic impacts of COVID-19 and even revise current economic practices that could result in a more equitable, sustainable global economy [17-19].

\section{Vulnerable Healthcare Workforce}

A critical component of providing quality healthcare for children is ensuring access to healthcare and a sufficient healthcare workforce [20]. Most resource-limited settings already have workforce challenges with minimal ability to absorb further losses [21, 22]. An international survey on pediatrician density published in early 2019 reported a median of 0.5 pediatricians per 100,000 children in low-income countries compared to 72 per 100,000 children in high-income countries [23]. Although pediatricians in resource-limited settings represent a relatively small proportion of those caring for children, this discrepancy highlights the fragility of the current systems. Important healthcare workforce expansions have been made in recent years; however, COVID-19 threatens to reverse these gains [24]. Tools have been developed and used to help human immunodeficiency virus (HIV) programs in LMICs adjust staffing in response to COVID-related disruptions to avoid interruption of critical HIV care [25•]. The sharing of these tools and lessons learned from their use to date could lessen some of the impact on the healthcare workforce and service delivery.

These healthcare workers must be protected. With the global pandemic, all countries sought to bolster supplies of personal protective equipment (PPE), with concomitantly reduced production capacity because of interrupted manufacturing and supply chains. Increased supply costs disadvantaged lower income countries, while well-resourced countries procured a disproportionate share of the available PPE. This disparity continues to place frontline healthcare workers in LMICs at increased risk of COVID-19 infection. Shortages of N95 masks have also put healthcare workers at risk while caring for other infectious diseases, such as tuberculosis (TB) and measles, in settings where effective infection prevention and control are already difficult. If large numbers of healthcare workers become ill and unable to continue meeting their responsibilities, this could have drastic short- and long-term consequences on child health, as the capacity to train new healthcare workers remains constrained in these settings [26-28].

\section{Interruption of Routine Health Services}

The interruption of non-COVID-19 preventive and curative health services may take a tremendous toll on child health. Infectious diseases and neonatal deaths represent the majority of under-5 mortality, with preterm birth complications, pneumonia, and intrapartum-related complications being the leading causes globally [5]. Closed clinics and deferment of routine care, limited travel, and disrupted supply chains during 
periods of widespread quarantine measures may reduce necessary vaccine access, medications, and other critical supplies. Approximately $40 \%$ of excess child deaths from indirect effects of COVID-19 are expected to be related to limited access to antibiotics for pneumonia and neonatal sepsis, oral rehydration for diarrhea, and immunizations for vaccine-preventable diseases, with additional large contributions from interruptions to antenatal care, neonatal care, and growth and nutrition monitoring $[6 \bullet \cdot$. The WHO has provided operational guidance for maintaining routine health services geared toward resource-limited settings, which-if effectively implemented-would reduce the extent and duration of interruptions [29].

In some settings, especially sub-Saharan Africa, TB, HIV, and malaria contribute to a significant proportion of child morbidity and mortality. For children with these diseases, interruptions in routine care will have further detrimental effects. Mathematical models estimate that potential short-term disruptions in HIV care (e.g., 6 months) could result in more than 500,000 excess deaths, with a $104 \%$ increase in new pediatric HIV infections due to interruptions in the prevention of mother-to-child transmission programs [30]. Other models have suggested that, through interruption of TB services, COVID-19 could result in an additional 6.3 million TB cases and 1.3 million TB-related deaths (among all ages) globally between 2020 and 2025 [31, 32]. Physical distancing and widespread mask wearing could potentially reduce TB transmission, but the effects are expected to be outweighed by disruption of TB services [33-35]. The ultimate outcome of these divergent effects on TB burden will only become apparent over time. Mitigating the indirect effects of COVID-19 on TB and HIV will depend on maintaining these crucial health services. Despite the challenges, innovative solutions to avoid service delivery interruptions for HIV and TB care are being implemented and lessons shared and include expanded community-based testing and treatment delivery, extended medication refills, and phone-based counseling and support [25• 36, 37]. Additionally, HIV and TB programs in LMICs offer many opportunities to support the COVID-19 response. For example, supply chains, laboratory, and pharmacy networks developed for HIV and TB care are being utilized to distribute relevant lab supplies and facilitate testing for SARSCoV-2 and could be used to help distribute COVID-19 treatments when available [25•].

Large-scale quarantines and physical distancing measures have led to dramatic decreases in routine childhood immunization of 25-66\% across diverse settings [38-42]. Globally, the COVID-19 pandemic has decreased vaccine supply chains, with United Nations Children's Fund (UNICEF) reporting a 70-80\% reduction in planned vaccine shipments [43]. By late May 2020, 80 million children worldwide were deemed already at increased risk for vaccine-preventable diseases due to immunization access issues [44]. Models estimate that sustaining routine immunization in sub-Saharan Africa would prevent 84 deaths in children for every 1 excess COVID-19 death attributable to the vaccination program [45•]. Delivery of routine immunizations has the potential to avert many preventable child deaths and must remain a priority. Specific advice for healthcare workers in resource-limited settings on maintaining routine immunizations during the pandemic, such as those from the Indian Academy of Pediatrics, is likely to be helpful [46]. Additionally, plans should be made now for catch-up programs addressing missed immunizations once pandemic restrictions are reduced.

\section{Mental Health, Child Protection, and Other Considerations}

At the outset of the pandemic, it was speculated that COVID19 would create a wave of mental health challenges for children due to interruption of education, isolation, increased poverty, food insecurity, and the risk of illness and death for themselves and family members. Social isolation and a lost feeling of belonging are among the highest risks for young people in these circumstances. The experience of prolonged stress in children may cause irreversible damage, hindering cognitive development and altering long-term health. The capacity to provide mental health services for children is woefully inadequate worldwide, with limited access even in highincome regions, but particularly in many resource-limited settings where the psychosocial impacts of COVID-19 are likely to exact a tremendous long-term toll on children's well-being $[47,48]$. Many of these concerns have been born out, with emerging data showing an increase in pediatric mental health issues $[49,50]$. The pandemic represents an opportunity to prioritize child and adolescent mental health needs and reimagine how pediatric mental health services could be improved and delivered globally. Innovations developed in response to COVID-19, including improved access to online educational resources about child mental health and provision of virtual mental health services, could continue and be strengthened post pandemic [51].

As social and community networks come under stress, children are at increased risk of violence, abuse, exploitation, and neglect $[52,53]$. As life continues to be disrupted by COVID19, many children face increased exposure to domestic violence and neglect from caregivers, especially where financial and health burdens combined with other stressors have increased; while access to adult observers who can detect and respond to abuse, such as teachers, law enforcement, and religious leaders, has decreased. Gender inequities may be further amplified, and vulnerable children could face an increased risk of being forced into early marriage, teen pregnancy, hazardous child labor, and human trafficking. Child protection services responsible for the prevention and response to violence, exploitation, and abuse of children in all contexts are 
already constrained in many resource-limited settings and maybe even less available to respond during the pandemic [54]. Support for caregivers must not be overlooked as a critical component of a holistic strategy to protect children during this crisis. Supporting caregivers' mental health and encouraging their development of positive parenting skills will have a catalytic effect on their children's mental health and wellbeing. In many LMICs, active community and civil society organizations established to support HIV- and TB-affected persons could be leveraged to support children and families affected by COVID-19 [25•].

Children of all ages rely on their primary caregivers to provide a sense of safety and security and to help them make sense of stressful or traumatic events. Like the HIV pandemic, which orphaned over 15 million children across sub-Saharan Africa, the direct and indirect impacts of COVID-19 will result in a large number of new orphans and vulnerable children in communities already stretched beyond capacity [55]. For children outside of parental care, investments should be made in family-based care alternatives. Additionally, children living in densely populated refugee camps are a particularly vulnerable subgroup that will require specific targeted protective interventions [56, 57].

\section{Urgent Call to Action}

Child health providers must continue to provide local, national, and international leadership for the COVID-19 response and advocate for high-quality care for children in their communities. All those committed to child health must join together in solidarity to demand a rapid, equitable response to COVID-19 that prioritizes preventive services and care for the most vulnerable children, especially those in resourcelimited settings. Additionally, equitable access for LMICs to COVID-19 treatment and prevention tools, including equitable vaccine access for healthcare workers, teachers, childcare workers, and families/children, must be ensured as the negative effects of COVID-19 on child health will disproportionately impact these settings. In a compelling and unified manner, the child health community must demand that political leaders prioritize global child health.

Table 1 lists a number of high-priority actions to mitigate COVID-19's effects on child health.

Sharing of best practices among all child health advocates is critical. A truly collaborative approach must specifically acknowledge that many widely applicable lessons on how to respond to the pandemic may arise from resource-limited settings. Healthcare workers in these settings are resilient, versatile, and innovative and draw on extensive experience in responding to infectious disease epidemics, including HIV, Ebola, malaria, measles, and TB, through the use of both technologically and nontechnologically based strategies to
Table 1 Priority actions to mitigate impacts of COVID-19 on global child health

1. Increase financial and technical support to high-need countries that foster local responses to mitigate the effects of COVID-19 on child health. Responses should be informed by shared evidence and international best practices but should be adapted to local contexts and must be driven by local health leadership and communities [63].

2. Rapidly and freely disseminate lessons learned and share best practices and guidelines, including open access to COVID-related scientific publications, so that practitioners in all settings can benefit from evolving knowledge and each other's experiences [59-61, 63, 64].

3. Ensure equitable distribution of PPE globally to protect all healthcare workers. Widely disseminate innovative methods to optimally create or reuse PPE, such as through safe decontamination. Support engineering and manufacturing of PPE locally, focusing on items that can be easily decontaminated and used safely and effectively multiple times.

4. Support ongoing programs that provide non-COVID-19 priority preventive and curative care for children, such as antenatal and neonatal care; immunization programs; nutrition support; diagnosis and treatment of diarrheal illness, pneumonia, TB, and HIV care; early childhood development programs; child protection services; and care of noncommunicable diseases, including through innovative delivery models $[6 \bullet \bullet]$.

5. Ensure timely, equitable inclusion of children in clinical trials of COVID-19 vaccines and therapeutics, and ultimately rapid, affordable, and equitable access for all children globally to any of these that prove to be effective.

6. Fund COVID-19 research in children with comorbidities to characterize the risk of severe disease, establish care protocols, determine therapeutic interventions, and determine prioritization for COVID-19 vaccination.

support community health $[58,59]$. In fact, examples of successful innovative responses by HIV programs in LMICs supported by the President's Emergency Plan for AIDS Relief (PEPFAR) [25•] and other strategies from Liberia, Rwanda, Peru, and Bangladesh have already been highlighted and could be more broadly adopted [60].

The many challenges notwithstanding, the response to COVID-19 may also provide opportunities. Resources mobilized to respond to COVID-19 could be synergistic with responses to other diseases and other efforts at health system strengthening [61]. Investments in health systems to rapidly deploy a SARS-CoV-2 vaccine could benefit routine vaccination programs. Diagnostic testing for SARS-CoV-2 could be paired with testing for HIV, TB, or other diseases. However, taking advantage of these and many other opportunities will require intention, planning, and a commitment to do so.

\section{Conclusion}

The global COVID-19 pandemic has demonstrated how interconnected our transnational world has become. In this crisis, 
we are confronted with critical choices and reminded of the moral imperative for equity. Will we engage in cooperative action that addresses every person's health in an equitable manner in order to help current and future generations overcome the widespread impact of this pandemic? Or will we miss this opportunity to rise and defend the well-being of our children? Will we utilize this crisis to fundamentally reenvision the health of children globally as a central priority rather than an afterthought [62]? We call on the child health community to partner together to limit the impact of COVID19 on all children globally.

Author Contribution AJGP, RMM, NES, and HH conceptualized and designed the review, drafted the initial manuscript, and reviewed and revised the manuscript. MM, LT, SMB, JHC, and MS contributed to the design of the review and critically reviewed and revised the manuscript for important intellectual content. All authors approved the final manuscript as submitted and agreed to be accountable for all aspects of the work.

Data Availability Not applicable.

Code Availability Not applicable.

\section{Declarations}

Conflict of Interest The authors have no financial relationships relevant to this article to disclose. JHC acts as an advisor/consultant for GSK, Pfizer, Moderna, and Merck Vaccines and is a principal investigator or co-principal investigator for immunization projects with funding from Sanofi Pasteur and the United States Centers for Disease Control. All other authors have no conflicts of interest relevant to this article to disclose.

Human and Animal Rights and Informed Consent This article does not contain any studies with human or animal subjects performed by any of the authors.

\section{References}

Papers of particular interest, published recently, have been highlighted as:

- Of importance

•. Of major importance

1. Coronavirus disease 2019 in children - United States, February 12April 2, 2020. MMWR Morb Mortal Wkly Rep. doi:https://doi.org/ 10.15585/mmwr.mm6914e4.

2. Dong Y, Mo X, Hu Y, Qi X, Jiang F, Jiang Z, et al. Epidemiology of COVID-19 among children in China. Pediatrics. 2020;145(6): e20200702. https://doi.org/10.1542/peds.2020-0702.

3. Lu X, Zhang L, Du H, Zhang J, Li YY, Qu J, et al. SARS-CoV-2 infection in children. N Engl J Med. 2020;382(17):1663-5. https:// doi.org/10.1056/NEJMc2005073.

4. Shekerdemian LS, Mahmood NR, Wolfe KK, Riggs BJ, Ross CE, McKiernan CA, et al. Characteristics and outcomes of children with coronavirus disease 2019 (COVID-19) infection admitted to US and Canadian pediatric intensive care units. JAMA Pediatr. 2020;174(9):868-73. https://doi.org/10.1001/jamapediatrics.2020. 1948.

5. Kassebaum N, Kyu HH, Zoeckler L, Olsen HE, Thomas K, Pinho C, et al. Child and adolescent health from 1990 to 2015: findings from the Global Burden of Diseases, Injuries, and Risk Factors 2015 Study. JAMA Pediatr. 2017;171(6):573-92. https://doi.org/ 10.1001/jamapediatrics.2017.0250.

6.• Roberton T, Carter ED, Chou VB, Stegmuller AR, Jackson BD, Tam Y, et al. Early estimates of the indirect effects of the COVID19 pandemic on maternal and child mortality in low-income and middle-income countries: a modelling study. Lancet Glob Health. 2020;8(7):e901-e8. https://doi.org/10.1016/s2214-109x(20) 30229-1 This study models the potential impact of the indirect effects of COVID-19, through increased poverty or disruption of routine health services, on maternal and under-5 mortality globally, highlighting the huge risk to child health despite limited negative directs impacts from COVID-19.

7. Lakner C, Yonzan N, Mahler DG, Aguilar RAC, Wu H. Updated estimates of the impact of COVID-19 on global poverty: looking back at 2020 and the outlook for 2021. 2021. https://blogs. worldbank.org/opendata/updated-estimates-impact-covid-19global-poverty-looking-back-2020-and-outlook-2021. Accessed April 8, 2021.

8. Voss R, Martin W, Laborde D. How much will global poverty increase because of COVID-19? 2020. https://www.ifpri.org/blog/ how-much-will-global-poverty-increase-because-covid- 19 . Accessed April 20, 2020.

9. United Nations. Policy brief: the impact of COVID-19 on children. 2020. https://www.un.org/sites/un2.un.org/files/policy brief on covid_impact_on_children_16_april_2020.pdf. Accessed April 20, 2020.

10. Brooks-Gunn J, Duncan GJ. The effects of poverty on children. Futur Child. 1997;7(2):55-71.

11. Lelijveld N, Seal A, Wells JC, Kirkby J, Opondo C, Chimwezi E, et al. Chronic disease outcomes after severe acute malnutrition in Malawian children (ChroSAM): a cohort study. Lancet Glob Health. 2016;4(9):e654-e62. https://doi.org/10.1016/S2214109X(16)30133-4.

12. Victora CG, Adair L, Fall C, Hallal PC, Martorell R, Richter L, et al. Maternal and child undernutrition: consequences for adult health and human capital. Lancet. 2008;371(9609):340-57. https://doi.org/10.1016/S0140-6736(07)61692-4.

13. Mendoza JA, Matshaba M, Makhanda J, Liu Y, Boitshwarelo M, Anabwani GM. Food insecurity and CD4\% among HIV+ children in Gaborone,Botswana. J Acquir Immune Defic Syndr. 2014;66(4): 414-8. https://doi.org/10.1097/qai.0000000000000190.

14. Abrams SA, Avalos A, Gray M, Hawthorne KM. High level of food insecurity among families with children seeking routine care at federally qualified health centers during the coronavirus disease 2019 pandemic. J Pediatr X. 2020;4:100044. https://doi.org/10. 1016/j.ympdx.2020.100044.

15. Dunn CG, Kenney E, Fleischhacker SE, Bleich SN. Feeding lowincome children during the COVID-19 pandemic. N Engl J Med. 2020;382(18):e40. https://doi.org/10.1056/NEJMp2005638.

16. Van Lancker W, Parolin Z. COVID-19, school closures, and child poverty: a social crisis in the making. Lancet Public Health. 2020;5(5):e243-e4. https://doi.org/10.1016/s2468-2667(20) 30084-0.

17. Moorty L, Mahajan S, Andronova Vincelette G, Izvorski I. A policy framework for mitigating the impact of the COVID-19 crisis. Washington: World Bank; 2020. https://openknowledge. worldbank.org/handle/10986/33776. Accessed April 9, 2021

18. Ibn-Mohammed T, Mustapha KB, Godsell J, Adamu Z, Babatunde KA, Akintade DD, et al. A critical analysis of the impacts of 
COVID-19 on the global economy and ecosystems and opportunities for circular economy strategies. Resour Conserv Recycl. 2021;164:105169. https://doi.org/10.1016/j.resconrec.2020. 105169.

19. Djankov S, Panizza U. COVID-19 in developing economies. London: CEPR Press; 2020.

20. Liang S, Macinko J, Yue D, Meng Q. The impact of the health care workforce on under-five mortality in rural China. Hum Resour Health. 2019;17(1):21. https://doi.org/10.1186/s12960-019-03575 .

21. World Health Organization. A universal truth: no health without a workforce. Geneva, Switzerland. 2014. https://www.who.int/ workforcealliance/knowledge/resources/GHWA-a universal truth_report.pdf. Accessed April 20, 2020.

22. Chen L, Evans T, Anand S, Boufford JI, Brown H, Chowdhury M, et al. Human resources for health: overcoming the crisis. Lancet. 2004;364(9449):1984-90. https://doi.org/10.1016/s0140-6736(04) 17482-5.

23. Harper BD, Nganga W, Armstrong R, Forsyth KD, Ham HP, Keenan WJ, et al. Where are the paediatricians? An international survey to understand the global paediatric workforce. BMJ Paediatr Open. 2019;3(1):11. https://doi.org/10.1136/bmjpo-2018-000397.

24. Afriyie DO, Nyoni J, Ahmat A. The state of strategic plans for the health workforce in Africa. BMJ Glob Health. 2019;4(Suppl 9): e001115. https://doi.org/10.1136/bmjgh-2018-001115.

25. Golin R, Godfrey C, Firth J, Lee L, Minior T, Phelps BR, et al. PEPFAR's response to the convergence of the HIV and COVID-19 pandemics in sub-Saharan Africa. J Int AIDS Soc. 2020;23(8): e25587. https://doi.org/10.1002/jia2.25587 This report describes adaptations that HIV programs in LMICs have taken to maintain HIV services in the face of COVID-19, demonstrating valuable lessons for other programs and health systems and providing concrete examples of opportunities to improve care delivery in response to COVID-19.

26. Cancedda C, Farmer PE, Kerry V, Nuthulaganti T, Scott KW, Goosby E, et al. Maximizing the impact of training initiatives for health professionals in low-income countries: frameworks, challenges, and best practices. PLoS Med. 2015;12(6):e1001840. https://doi.org/10.1371/journal.pmed.1001840.

27. Mullan F, Frehywot S, Omaswa F, Buch E, Chen C, Greysen SR, et al. Medical schools in sub-Saharan Africa. Lancet. 2011;377(9771):1113-21. https://doi.org/10.1016/S01406736(10)61961-7.

28. Crisp N, Chen L. Global supply of health professionals. N Engl J Med. 2014;370(10):950-7. https://doi.org/10.1056/ NEJMra1111610.

29. World Health Organization. Maintaining essential health services: operational guidance for the COVID-19 context. WHO, Geneva, Switzerland. 2020. https://www.who.int/publications/i/item/WHO2019-nCoV-essential-health-services-2020.1. Accessed April 9, 2021.

30. Jewell BL, Mudimu E, Stover J, Ten Brink D, Phillips AN, Smith JA, et al. Potential effects of disruption to HIV programmes in subSaharan Africa caused by COVID-19: results from multiple mathematical models. Lancet HIV. 2020;7(9):e629-e40. https://doi.org/ 10.1016/s2352-3018(20)30211-3.

31. Stop TB Partnership. The potential impact of the COVID-19 response on tuberculosis in high-burden countries: a modelling analysis. 2020. http://www.stoptb.org/assets/documents/news/ Modeling\%20Report_1\%20May\%202020_FINAL.pdf. Accessed May 18, 2020.

32. Hogan AB, Jewell BL, Sherrard-Smith E, Vesga JF, Watson OJ, Whittaker C, et al. Potential impact of the COVID-19 pandemic on HIV, tuberculosis, and malaria in low-income and middle-income countries: a modelling study. Lancet Glob Health. 2020;8(9): e1132-e41. https://doi.org/10.1016/s2214-109x(20)30288-6.
33. McQuaid CF, McCreesh N, Read JM, Sumner T, Houben R, White $\mathrm{RG}$, et al. The potential impact of COVID-19-related disruption on tuberculosis burden. Eur Respir J. 2020;56(2):2001718. https://doi. org/10.1183/13993003.01718-2020.

34. Chen H, Zhang K. Insight into the impact of the COVID-19 epidemic on tuberculosis burden in China. Eur Respir J. 2020;56(3): 2002710. https://doi.org/10.1183/13993003.02710-2020.

35. Driessche KV, Mahlobo PZ, Venter R, Caldwell J, Jennings K, Diacon AH, et al. Face masks in the post-COVID-19 era: a silver lining for the damaged tuberculosis public health response? Lancet Respir Med. 2021;9(4):340-2. https://doi.org/10.1016/s22132600(21)00020-5.

36. Loveday M, Cox H, Evans D, Furin J, Ndjeka N, Osman M, et al. Opportunities from a new disease for an old threat: extending COVID-19 efforts to address tuberculosis in South Africa. S Afr Med J. 2020;110(12):1160-7. https://doi.org/10.7196/SAMJ.2020. v110i12.15126.

37. Keene C, Mohr-Holland E, Cassidy T, Scott V, Nelson A, Furin J, et al. How COVID-19 could benefit tuberculosis and HIV services in South Africa. Lancet Respir Med. 2020;8(9):844-6. https://doi. org/10.1016/s2213-2600(20)30311-8.

38. Bramer CA, Kimmins LM, Swanson R, Kuo J, Vranesich P, Jacques-Carroll LA, et al. Decline in child vaccination coverage during the COVID-19 pandemic - Michigan Care Improvement Registry, May 2016-May 2020. MMWR Morb Mortal Wkly Rep. 2020;69(20):630-1. https://doi.org/10.15585/mmwr.mm6920e1.

39. Santoli JM, Lindley MC, DeSilva MB, Kharbanda EO, Daley MF, Galloway L, et al. Effects of the COVID-19 pandemic on routine pediatric vaccine ordering and administration - United States, 2020. MMWR Morb Mortal Wkly Rep. 2020;69(19):591-3. https://doi. org/10.15585/mmwr.mm6919e2.

40. Saso A, Skirrow H, Kampmann B. Impact of COVID-19 on immunization services for maternal and infant vaccines: results of a survey conducted by Imprint-the immunising pregnant women and infants network. Vaccines. 2020;8(3):556. https://doi.org/10.3390/ vaccines 8030556 .

41. Chandir S, Siddiqi DA, Setayesh H, Khan AJ. Impact of COVID19 lockdown on routine immunisation in Karachi, Pakistan. Lancet Glob Health. 2020;8(9):e1118-e20. https://doi.org/10.1016/s2214109x(20)30290-4.

42. Chandir S, Siddiqi DA, Mehmood M, Setayesh H, Siddique M, Mirza A, et al. Impact of COVID-19 pandemic response on uptake of routine immunizations in Sindh, Pakistan: an analysis of provincial electronic immunization registry data. Vaccine. 2020;38(45): 7146-55. https://doi.org/10.1016/j.vaccine.2020.08.019.

43. UNICEF. Geneva Palais briefing note on the impact of COVID-19 mitigation measures on vaccine supply and logistics. 2020. https:// www.unicef.org/press-releases/geneva-palais-briefing-noteimpact-covid-19-mitigation-measures-vaccine-supply-and. Accessed June 1, 2020.

44. At least 80 million children under one at risk of diseases such as diphtheria, measles and polio as COVID-19 disrupts routine vaccination efforts, warn Gavi, WHO and UNICEF. 2020. https://www. who.int/news-room/detail/22-05-2020-at-least-80-millionchildren-under-one-at-risk-of-diseases-such-as-diphtheria-measlesand-polio-as-covid-19-disrupts-routine-vaccination-efforts-warngavi-who-and-unicef. Accessed June 1, 2020.

45. Abbas K, Procter SR, van Zandvoort K, Clark A, Funk S, Mengistu $\mathrm{T}$, et al. Routine childhood immunisation during the COVID-19 pandemic in Africa: a benefit-risk analysis of health benefits versus excess risk of SARS-CoV-2 infection. Lancet Glob Health. 2020;8(10):e1264-e72. https://doi.org/10.1016/s2214-109x(20) 30308-9 This study models the risk and benefits of maintaining routine childhood immunization programs during COVID-19. This highlights the risk to children of interrupting this key health intervention and provides 
evidence for policymakers to make rationale decisions that prioritize child health.

46. Kasi SG, Dhir SK, Verma S, Pemde HK, Balasubramanian S, Agarwalla S, et al. Immunization during the COVID-19 pandemic: recommendations from Indian Academy of Pediatrics advisory committee on vaccines and immunization practices. Indian Pediatr. 2020;57(12):1147-52. https://doi.org/10.1007/s13312020-2071-8.

47. Kakuma R, Minas H, van Ginneken N, Dal Poz MR, Desiraju K, Morris JE, et al. Human resources for mental health care: current situation and strategies for action. Lancet. 2011;378(9803):1654 63. https://doi.org/10.1016/s0140-6736(11)61093-3.

48. Kieling C, Baker-Henningham H, Belfer M, Conti G, Ertem I, Omigbodun $\mathrm{O}$, et al. Child and adolescent mental health worldwide: evidence for action. Lancet. 2011;378(9801):1515-25. https://doi.org/10.1016/s0140-6736(11)60827-1.

49. Meherali S, Punjani N, Louie-Poon S, Abdul Rahim K, Das JK, Salam RA, et al. Mental health of children and adolescents amidst COVID-19 and past pandemics: a rapid systematic review. Int J Environ Res Public Health. 2021;18(7):3432. https://doi.org/10. 3390/ijerph18073432.

50. Panda PK, Gupta J, Chowdhury SR, Kumar R, Meena AK, Madaan $\mathrm{P}$, et al. Psychological and behavioral impact of lockdown and quarantine measures for COVID-19 pandemic on children, adolescents and caregivers: a systematic review and meta-analysis. J Trop Pediatr. 2021;67(1):fmaa122. https://doi.org/10.1093/tropej/ fmaal22.

51. Kola L, Kohrt BA, Hanlon C, Naslund JA, Sikander S, Balaji M, et al. COVID-19 mental health impact and responses in low-income and middle-income countries: reimagining global mental health. Lancet Psychiatry. 2021. https://doi.org/10.1016/s2215-0366(21) 00025-0.

52. Joint leaders' statement - violence against children: a hidden crisis of the COVID-19 pandemic. 2020. https://www.who.int/newsroom/detail/08-04-2020-joint-leader-s-statement\%2D\%2Dviolence-against-children-a-hidden-crisis-of-the-covid-19pandemic. Accessed June 1, 2020.

53. COVID-19: Children at heightened risk of abuse, neglect, exploitation and violence amidst intensifying containment measures. 2020. https://www.unicef.org/press-releases/covid-19-childrenheightened-risk-abuse-neglect-exploitation-and-violence-amidst. Accessed June 1, 2020.

54. End violence against children (EVAC) Taskforce. Child protection during the COVID-19 response. 2020. https://www.unicefusa.org/ sites/default/files/EV A C \% $20 \% 20$ P OLICY\% $20 \%$ 20RECOMMENDATIONS\%20COVID\%20final.pdf. Accessed June 8, 2020.
55. Bryant M, Beard J. Orphans and vulnerable children affected by human immunodeficiency virus in sub-Saharan Africa. Pediatr Clin N Am. 2016;63(1):131-47. https://doi.org/10.1016/j.pcl.2015.08. 007.

56. Iacobucci G. Covid-19: Doctors warn of humanitarian catastrophe at Europe's largest refugee camp. BMJ. 2020;368:m1097. https:// doi.org/10.1136/bmj.m1097.

57. Raju E, Ayeb-Karlsson S. COVID-19: how do you self-isolate in a refugee camp? Int J Public Health. 2020;65(5):515-7. https://doi. org/10.1007/s00038-020-01381-8.

58. Beratarrechea A, Lee AG, Willner JM, Jahangir E, Ciapponi A, Rubinstein A. The impact of mobile health interventions on chronic disease outcomes in developing countries: a systematic review. Telemed J E Health. 2014;20(1):75-82. https://doi.org/10.1089/ tmj.2012.0328.

59. Kapata N, Ihekweazu C, Ntoumi F, Raji T, Chanda-Kapata P, Mwaba P, et al. Is Africa prepared for tackling the COVID-19 (SARS-CoV-2) epidemic. Lessons from past outbreaks, ongoing pan-African public health efforts, and implications for the future. Int J Infect Dis. 2020;93:233-6. https://doi.org/10.1016/j.ijid.2020. 02.049 .

60. Phillips DE, Bhutta ZA, Binagwaho A, Boerma T, Freeman MC, Hirschhorn LR, et al. Learning from exemplars in global health: a road map for mitigating indirect effects of COVID-19 on maternal and child health. BMJ Glob Health. 2020;5(7):e003430. https://doi. org/10.1136/bmjgh-2020-003430.

61. Mejia R, Hotez P, Bottazzi ME. Global COVID-19 efforts as the platform to achieving the sustainable development goals. Curr Trop Med Rep. 2020;7:1-5. https://doi.org/10.1007/s40475-020-00209y.

62. World Health Organization, UNICEF. Putting children at the centre of the sustainable development goals. 2020. https:/www.who.int/ publications/i/item/putting-children-at-the-centre-of-thesustainable-development-goals. Accessed April 6, 2021.

63. Cash R, Patel V. Has COVID-19 subverted global health? Lancet. 2020;395(10238):1687-8. https://doi.org/10.1016/s0140-6736(20) 31089-8.

64. Semaan A, Audet C, Huysmans E, Afolabi B, Assarag B, BankeThomas A, et al. Voices from the frontline: findings from a thematic analysis of a rapid online global survey of maternal and newborn health professionals facing the COVID-19 pandemic. BMJ Glob Health. 2020;5(6):e002967. https://doi.org/10.1136/bmjgh-2020002967.

Publisher's Note Springer Nature remains neutral with regard to jurisdictional claims in published maps and institutional affiliations. 